\title{
PARTICIPAÇÃO E PROTAGONISMO FEMININO NOS PROGRAMAS DE FOMENTO À AGRICULTURA FAMILIAR NO INTERIOR PAULISTA
}

\author{
PARTICIPATION AND FEMININE PROTAGONISM IN THE PROMOTION PROGRAMS FOR FAMILY AGRICULTURE IN \\ THE PAULISTA INTERIOR
}

\section{RESUMO}

Nos assentamentos rurais de Araras e Jaboticabal, as mulheres associadas à Organização de Mulheres Assentadas e Quilombolas do Estado de São Paulo (OMAQUESP), são protagonistas no que se refere à participação em Programas Governamentais de Apoio à Agricultura Familiar. Nesse sentido, o objetivo desse trabalho é o de demonstrar, a partir das ações por elas desempenhadas no Programa de Aquisição de Alimentos (PAA), Programa Nacional de Alimentação Escolar (PNAE) e o Programa Paulista de Agricultura de Interesse Social (PPAIS), como constroem suas lutas contra as invisibilidades e pelo reconhecimento de seus trabalhos, criando estratégias que promovam a transformação de suas comunidades rurais. Por meio de entrevistas, trabalhos de campo e de referenciais bibliográficos, observouse ainda que, o desempenho das mulheres, no comando desses Programas, contribui para a diversidade de produção agrícola, em realidades como a do Estado e dos municípios de Araras e Jaboticabal, caracterizadas pelo domínio da produção de commodities do agronegócio.

Palavras-chave: Assentadas; OMAQUESP; Agricultura familiar; Programas Governamentais.

\section{ABSTRACT}

In the rural settlements of Araras and Jaboticabal, women associated in the São Paulo State Organization of Settled and Quilombola Women (OMAQUESP) are protagonists in participating in Government Support Programs for Family Farming. In this sense, the objective of this work is to demonstrate, from the actions performed by them in the Food Acquisition Program (PAA), National School Feeding Program (PNAE) and the Paulista Agriculture Program of Social Interest (PPAIS), how they build their struggles against invisibility and the recognition of their work, creating strategies that promote the transformation of their rural communities. Through interviews, fieldwork and bibliographic references, it was also observed that the performance of women, in charge of these programs, contributes to the diversity of agricultural production, in realities such as the State and the municipalities of Araras and Jaboticabal, characterized by dominance of agribusiness commodity production.

Keywords: Rural Women; OMAQUESP; Family Farming; Government Programs.

\author{
Fernando Veronezzi Silva ${ }^{\text {a }}$ \\ Elpidio Serra ${ }^{b}$ \\ a Universidade Estadual de Londrina (UEL), \\ Londrina, PR, Brasil \\ b Universidade Estadual de Maringá (UEM), \\ Maringá, PR, Brasil
}

DOI: $10.12957 /$ geouerj.2020.34267

Correpondência:fernandoveronezzi117@hotmail.com

Recebido em: 21 mai. 2018

Revisado em: 22 abr 2020

Aceito em: 23 mai. 2020 


\section{INTRODUÇÃO}

As Ciências Humanas, durante anos, desconsideraram as mulheres, enquanto agentes de produção do espaço. $O$ conhecimento geográfico, na maioria das vezes, esteve atrelado a uma análise que valorizava a ação dos homens em detrimento das mulheres. A abordagem da mulher, enquanto um agente essencial de produção e transformação do espaço (SILVA, 2003) foi menosprezada por muito tempo.

Veleda da Silva (2013) considera que a falta de esforços para inserir as perspectivas que envolvem as questões de gênero no campo da Geografia, pode decorrer da ausência de conhecimento sobre as múltiplas possibilidades de interpretação de novos arranjos socioespaciais, pois ainda se percebe uma estrutura patriarcal nas esferas de poder, bem como na Geografia e na Academia brasileira, marcadas pela desvalorização dessas temáticas de estudo [...] (VELEDA DA SILVA, 2013, p.114).

\footnotetext{
a Geografia brasileira [...] precisa estar atenta para esses [...] movimentos sociais como mais um instrumento de análise do social que, consequentemente, produz novos espaços geográficos. Incorporar as contribuições teóricas do feminismo e estudar empiricamente como o espaço é modificado por esses movimentos é tarefa emergente para quem quer compreender os novos espaços geográficos (VELEDA DA SILVA, 2000, s.p).
}

Silva (2003) acrescenta a essa discussão, a ideia de que a supressão da mulher, enquanto sujeito social vem sendo manifestada por geógrafas feministas, que não medem esforços para incluir os feminismos e a perspectiva de gênero em estudos dessa Ciência. As multiplicidades de abordagens dessas correntes de pensamento podem ser consideradas como "[...] expressões de sua riqueza teórico-metodológico, e elas se convertem também em energias que renovam os debates e o avanço científico" (SILVA, 2009, p. 50).

A partir dessas constatações, as reflexões aqui apresentadas têm como objetivo discutir a participação e protagonismo das assentadas vinculadas à Organização de Mulheres Assentadas e Quilombolas do Estado de São Paulo (OMAQUESP), através de três Programas Governamentais de fomento à agricultura familiar: Programa de Aquisição de Alimentos (PAA), Programa Nacional de Alimentação Escolar (PNAE), ambos de âmbito federal e o Programa Paulista de Agricultura de Interesse Social (PPAIS), de domínio estadual, nos assentamentos rurais de Araras e Jaboticabal, interior de São Paulo, buscando entender de que maneira elas constroem suas lutas cotidianas contra as invisibilidades e pelo reconhecimento de seus trabalhos, criando estratégias que promovam a transformação de suas comunidades rurais, bem como em outras escalas de ação.

A OMAQUESP compreende mulheres assentadas e quilombolas de várias regiões do Estado de São Paulo e dentre os objetivos da Organização, criada oficialmente em 2002, estão:

Formar diretrizes e promover, em todos os níveis da sociedade, atividades e projetos, que visem a defesa e proteção, dos direitos e interesses das mulheres assentadas, acampadas e quilombolas do Estado de São Paulo, visando a eliminação de discriminações, que atingem, essas esferas referidas 
mulheres e suas comunidades, bem como promover a sua plena integração na vida sócio-econômica e político-cultural. Desenvolver estudos, debates, pesquisas e projetos, relativos à problemática enfrentada por essas mulheres e suas Comunidades, em cada localidade, visando eliminação de discriminações, e problemas existentes através de projetos ou ações, próprias ou conjuntas, através de lutas sociais e através de instrumentos administrativos ou judiciais, aos Poderes Executivo, Legislativo e Judiciário, no âmbito Municipal, Estadual e Federal, visando a busca de recursos, meios e ações práticas, para o desenvolvimento de seus projetos, que ofereçam a essas mulheres e suas comunidades, alternativas para o progresso social, econômico e cultural (OMAQUESP, 2005).

A OMAQUESP é um movimento que potencializa ações de suas militantes no desenvolvimento de lutas contra a opressão, submissão, discriminação e dominação, além da defesa de Programas e Projetos econômicos, sociais, culturais e ambientais e que visam transformações nas comunidades rurais onde as mulheres assentadas vivem. O movimento é amplo, reúne uma série de motivações e pautas, e sua amplitude não poderia ser abarcada nesse texto. Embora o movimento englobe as mulheres quilombolas, nesse ensaio, serão observadas apenas a participação e o protagonismo das assentadas nos Programas governamentais e nos assentamentos rurais já citados.

Os resultados estruturados nesse texto foram obtidos a partir da realização de entrevistas, de trabalhos de campo e do levantamento bibliográfico.

As mulheres entrevistadas foram selecionadas a partir da indicação da Assentada 4 (2016), pois o pesquisador já a conhecia por conta de pesquisas anteriores ${ }^{1}$. A sugestão de nomes de outras mulheres para participar das entrevistas tinha dois eixos como critérios principais: ser associada à OMAQUESP e ter no mínimo cinco anos de vivência em assentamentos rurais. Dessa forma, a partir desses elementos, são apresentados nesse texto, relatos baseados nas falas de seis mulheres de dois munícipios paulistas: Araras e Jaboticabal.

As entrevistadas não foram identificadas pelo nome verdadeiro, a fim de preservar a identidade das mesmas e aqui são apresentadas como Assentada 1 (Araras); Assentada 2 (Araras); Assentada 3 (Araras); Assentada 4 (Jaboticabal); Assentada 5 (Jaboticabal) e Assentada 6 (Jaboticabal). Nas referências organizadas no final do artigo são apresentadas outras informações de cada uma das entrevistadas. Outro fator a ser considerado é que, as citações são apresentadas no texto, contendo erros comuns da linguagem oral, pois foram transcritas de maneira fiel à fala das mulheres.

O roteiro das entrevistas foi desenvolvido com base em um plano flexível, no qual eram inseridos novos questionamentos, dependendo dos rumos que as narrativas tomavam (conforme as respostas eram reveladas, o pesquisador complementava as questões). As principais indagações versavam sobre a participação das assentadas na OMAQUESP, da origem da Organização aos dias atuais; a estrutura do movimento; os principais

\footnotetext{
${ }^{1}$ VERONEZZI, Fernando. Os trabalhadores rurais e a luta pela terra na região de Jaboticabal (SP): A conquista do assentamento rural
} de Córrego Rico. 2013. 145f. Dissertação (Mestrado em Geografia). Universidade Estadual de Maringá, Maringá-PR. 
projetos, das relações com outros movimentos sociais e das dificuldades cotidianas enfrentadas pelas mulheres rurais.

Após essa breve introdução, aponta-se que o artigo está estruturado em duas seções, sendo a primeira, uma breve caracterização geográfica da produção agrícola do recorte espacial em questão: o Estado de São Paulo e os municípios de Araras e Jaboticabal. Posteriormente, são discutidos três Programas de fomento à Agricultura familiar PAA, PNAE e PPAIS, sob a perspectiva das ações realizadas pelas mulheres assentadas da OMAQUESP.

\section{CONCENTRAÇÃO DA PRODUÇÃO AGRÍCOLA NO ESTADO DE SÃO PAULO E NOS MUNICíPIOS DE ARARAS E JABOTICABAL: BREVE CARACTERIZAÇÃO}

O Estado de São Paulo é caracterizado a partir de uma agricultura altamente tecnificada, voltada à produção de culturas como cana-de-açúcar e laranja (SAFFIOTI; FERRANTE, 1983), principais commodities do agronegócio paulista. A priorização da produção dessas culturas, a partir da destinação de grandes áreas para a sua produção, bem como de investimentos estatais e privados, marginaliza o trabalho daqueles que investem na diversificação da produção, como as realizadas nos assentamentos rurais, por exemplo.

Para se ter uma ideia desse panorama, de acordo com dados apresentados pelo Instituto de Economia Agrícola, vinculado à Secretaria de Agricultura e Abastecimento do Estado de São Paulo, na safra de 2007/2008, cana-de-açúcar, laranja, milho, café e soja, foram as culturas que tiveram maior produção e área destinadas a seu cultivo no Estado (SÃO PAULO, 2008), característica mantida, na safra de 2015/2016, destacando aumento de produção para todas as culturas mencionadas anteriormente; pequena diminuição de área para algumas (cana-de-açúcar -1\%, laranja -2\% e milho 3,5\%) e aumento para outras (café +0,46\%, soja $+6,7 \%$ ) (ANGELO et al, 2016), sendo o Estado caracterizado por uma produção agrícola pouco diversificada.

No que se refere ao valor das duas principais commodities paulistas, a cana-de-açúcar representa 59,3\%, e a laranja, $12,6 \%$, sendo que, esses dois produtos corresponderam a mais de $70 \%$ do valor da produção agrícola do Estado no triênio de 2010 a 2012, de acordo com informações da pesquisa 'Contribuições da FAPESP ao desenvolvimento da Agricultura no Estado de São Paulo (AGÊNCIA FAPESP, 2016).

Em relação à produção agrícola municipal, o contexto produtivo de Araras e Jaboticabal (Figura 1) é semelhante à do conjunto do Estado, sendo grandes extensões destinadas à produção de commoddities, da qual, a cana-de açúcar é a líder absoluta em área de produção nos dois municípios (SÃO PAULO, 2008). 
Figura 1. Localização dos municípios de Araras e Jaboticabal no Estado de São Paulo. Fonte: IBGE, 2010.

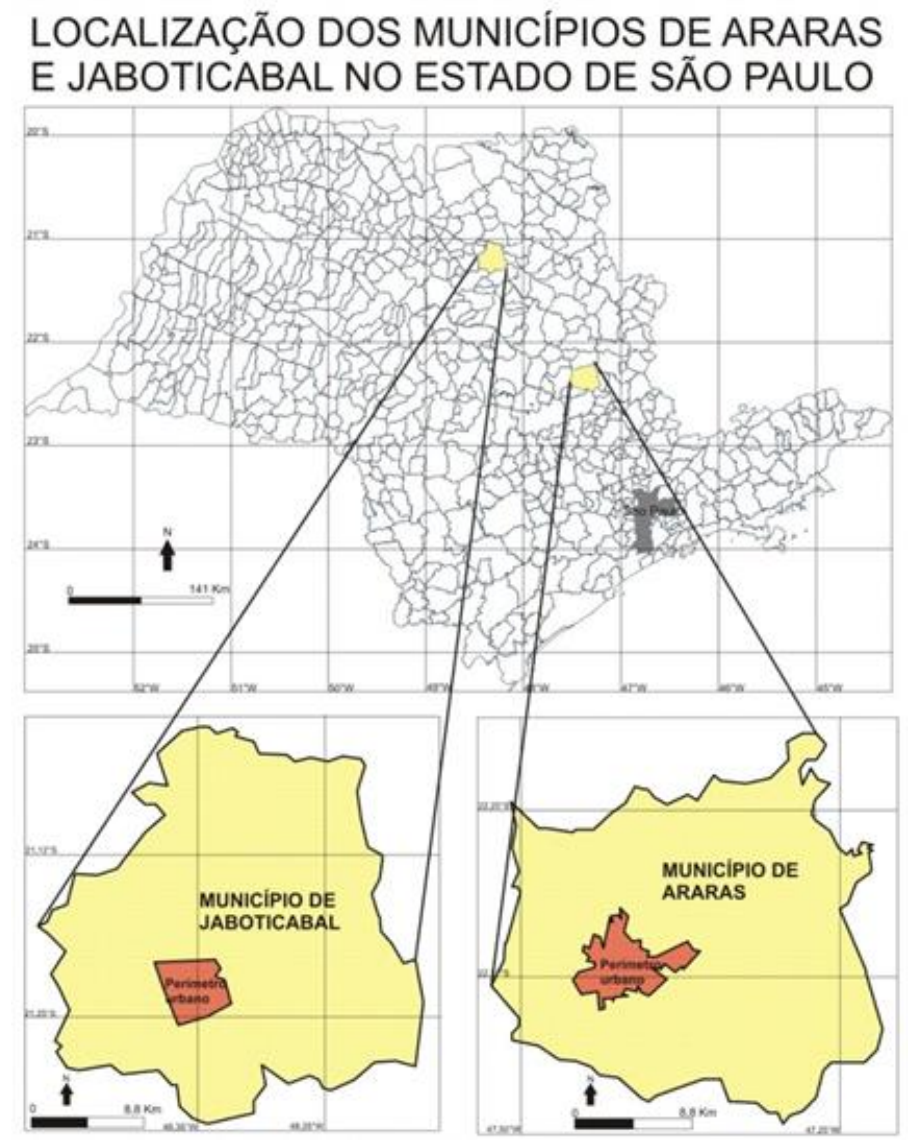

Compreendendo o papel que a cana-de-açúcar exerce nas realidades municipais, Jaboticabal ocupa a sexta $\left(6^{\circ}\right)$ posição e Araras a trigésima primeira $\left(31^{\circ}\right)$ (SAO PAULO, 2008) entre os municípios paulistas maiores produtores de cana-de- açúcar (nesse caso, considerando apenas a área de produção).

Além da cana-de-açúcar, em Araras, laranja e milho são os outros dois produtos mais cultivados na área municipal. Já em Jaboticabal, depois da cana-de-açúcar, amendoim e gramíneas, são as outras duas culturas mais produzidas no município (SAO PAULO, 2008).

A produção de commodities é concentradora de capital, tecnologias e terra, elimina diversos postos de trabalho através da mecanização e promove prejuízos econômicos, ambientais (VERONEZZI, 2012) e sociais, sendo tal contexto contrário às "[...] propostas de politicas que garantam a soberania alimentar e a reforma agrária" (MENDONÇA, 2006, p. 04).

Por meio dessa sucinta caracterização da produção agrícola estadual e municipal, observa-se que, por mais que São Paulo seja a unidade da Federação que "[...] ostenta os mais altos níveis de capitalização, de produtividade e de renda agrícola [...]", depende de outras áreas do país para assegurar a alimentação de sua população (SAFFIOTI; FERRANTE, 1983, p. 70), já que privilegia a concentração e a produção das commodities 
do agronegócio, em detrimento da policultura praticada em pequenas propriedades pelos assentados, quilombolas e outras comunidades tradicionais.

A produção agrícola paulista é concentrada e nesse contexto, compreender os Programas Governamentais de fomento à agricultura familiar por meio da participação e do protagonismo das mulheres assentadas de Araras e Jaboticabal se justifica, sendo os mesmos compreendidos como estratégias de diversificação da produção e de enfrentamento e resistência à realidade em que vivem.

\section{PAA, PNAE E PPAIS EM ARARAS E JABOTICABAL SOB A PERSPECTIVA DA PARTICIPAÇÃO DAS MULHERES}

\section{ASSENTADAS}

No sistema capitalista de produção, a questão econômica “[...] sempre foi pensada em bases patriarcais: agressiva, penetrante e opressiva" (PACHECO, 1998, p.61). No que se refere à divisão do trabalho no campo, parte do princípio de que o homem é responsável pelo trabalho produtivo e as mulheres do trabalho reprodutivo. Enquanto para os homens é ofertado tudo o que se associa ao mercado, às mulheres Ihes é cobrado o trabalho de casa, os cuidados das hortas, dos animais de pequeno porte (geralmente o que é voltado ao consumo da família) e dos filhos (NOBRE, 1998).

No campo, são as mulheres, as mais preocupadas em participar de organizações ou grupos que possuem engajamentos voltados às questões sociais (MOURÃO, 2013) e culturais e, que envolvem a busca pela cidadania plena, enquanto que os homens se interessam mais para a produção de culturas que tenham mais valor de mercado.

Uma das assentadas entrevistadas argumenta que: "A gente se importa mais com o social e com o meio ambiente do que os homens [...] nos movimentos que a gente participa têm essa discussão" (ASSENTADA 6, 2016). Outra complementa tal consideração quando coloca que, os homens se interessam geralmente, pela execução de empreendimentos agropecuários que resultem quantidades maiores de renda (ASSENTADA 4, 2016).

Em um dos trabalhos de campo realizado no assentamento de Jaboticabal, organizados em uma roda de discussão (um grupo de mulheres assentadas e o pesquisador), uma delas faz a seguinte revelação:

Devia ter grupo de homens pra sentar e conversar abertamente da mesma forma que a gente [...] pra discuti os Programa, os Projeto. Parece que os homens não pede conselho, não conversa com os outros. Isso é uma coisa cultural machista do brasileiro (ASSENTADA 4, 2016).

A assentada 4 (2016) ainda indica que, os homens não se interessam tanto pro Programas Governamentais, porque "[...] eles falam que dá pouco dinheiro [...]" (ASSENTADA 4, 2016). Nos 
assentamentos estudados, as mulheres são as mais preocupadas e empenhadas na execução de Programas Governamentais de apoio à agricultura familiar e na busca por estratégias de transformação e desenvolvimento de suas comunidades.

Participando da OMAQUESP, que possui várias frentes de luta e resistência, das quais, a busca por estratégias que visam à criação e à qualificação de Programas Governamentais de fomento à agricultura familiar, estão entre algumas das pautas do movimento, as mulheres resistem, procuram soluções para os problemas, criam alternativas, compartilham situações, incorporam novas demandas e dinamizam a produção, amparadas por esse coletivo.

Por meio das ações das mulheres da OMAQUESP são desenvolvidas práticas que possibilitam mudanças tanto nas realidades locais quanto em outras escalas, nos espaços privados e nos espaços públicos. Nos movimentos sociais, por meio da interação com outros coletivos, se desenvolvem contribuições para a construção de políticas que cobrem ações para a resolução e minimização de problemas (NOBRE, 1998). A OMAQUESP, segundo as entrevistadas, trabalha nesse sentido: potencializar a formação de mulheres engajando-as na superação dessas questões.

Informações apresentadas pelas assentadas consideram que, em vários casos que conhecem, o sustento da família é proveniente de ações desenvolvidas pelas mulheres, que buscam produzir determinados gêneros alimentícios, acessam os Programas e Políticas Públicas e que garantem a geração de renda (ASSENTADA 1, 2016; ASSENTADA 4, 2016).

Os dois assentamentos em questão, são áreas pequenas, das quais a diversificação produtiva e a participação em Programas e Projetos governamentais são essenciais, como indica a assentada 4: "A gente tem que busca produzi de tudo, luta pelos projetos [...] os assentamentos são pequenos na nossa região" (ASSENTADA 4, 2016).

Para comprovar o que menciona a Assentada 4 (2016), os dados organizados na tabela 1, demonstram informações que caracterizam os assentamentos de Araras e Jaboticabal, como a área que ocupam (total em hectares), o número de lotes, o ano de criação e o domínio da terra.

Tabela 1. Caracterização dos assentamentos rurais de Araras-SP e Jaboticabal-SP. Fonte: ITESP,2016.

\begin{tabular}{cccccc}
\hline Municípios & Assentamentos & Total (ha) & Lotes & Ano de criação & Domínio da Terra \\
\hline Araras & Araras I & 82,73 & 6 & 1984 & Estadual \\
Araras & Araras II & 208,99 & 14 & 1984 & Estadual \\
Araras & Araras III & 367,87 & 46 & 1997 & Estadual \\
Araras & Araras IV & 40,18 & 30 & 2004 & Estadual \\
Jaboticabal & Córrego Rico & 468,08 & 47 & 1998 & Estadual \\
\hline
\end{tabular}


Mesmo em áreas pequenas, as assentadas procuram estabelecer uma produção agrícola diferente daquela baseada na monocultura de commodities, como a que acontece no contexto geral do Estado de São Paulo e nos municípios de Araras e Jaboticabal, discutida na primeira seção do texto, o que pode ser observado de acordo com as informações do Quadro 1, que apresenta a diversidade produtiva nos assentamentos.

Quadro 1. Principais Produtos dos Assentamentos estudados. Fonte: ITESP, 2016.

\begin{tabular}{|c|l|}
\hline Assentamentos & \multicolumn{1}{c|}{ Gêneros Agrícolas } \\
\hline Araras I & $\begin{array}{l}\text { Abacate, abobrinha, alface, almeirão, arroz, beterraba, brócolis, cebolinha, coentro, } \\
\text { espinafre, laranja, limão, mandioca de mesa, mandioca indústria, milho, repolho, } \\
\text { rúcula, salsinha e tangerina }\end{array}$ \\
\hline Araras II & Banana nanica, cana forrageira, laranja, mandioca de mesa, mandioca indústria e milho \\
\hline Araras III & $\begin{array}{l}\text { Abobrinha brasileira, abóbora seca, abobrinha italiana, alface americana, alface crespa, } \\
\text { alface lisa, almeirão, arroz, banana nanica, banana prata, Berinjela, beterraba, brócolis, } \\
\text { café, cana forrageira, cebolinha, cheiro verde, chicória, couve, couve-flor, espinafre, } \\
\text { feijão, jaca, jiló, limão, mandioca de mesa, mandioca indústria, manga, milho, milho } \\
\text { silagem, milho verde, pepino japonês, pimentão, quiabo, repolho, rúcula e tangerina }\end{array}$ \\
\hline Jaras IV & $\begin{array}{l}\text { Abobrinha brasileira, alface americana, alface crespa, banana nanica, banana prata, } \\
\text { batata doce, berinjela, beterraba, café, cenoura, cheiro verde, chicória, coentro, couve, } \\
\text { feijão da seca, feijão das águas, feijão de corda, feijão mungo (moyashi), jiló, lima, } \\
\text { mandioca de mesa, milho, milho safrinha, milho verde, quiabo, rabanete e rúcula }\end{array}$ \\
\hline Jaboticabal & $\begin{array}{l}\text { Abóbora seca, abobrinha, arroz, banana maçã, banana nanica, berinjela, café, cana } \\
\text { forrageira, feijão da seca, feijão das águas, feijão de corda, goiaba de mesa, laranja, } \\
\text { limão, mandioca de mesa, manga, maxixe, milho, mucuna semente, pupunha, quiabo } \\
\text { e urucum }\end{array}$ \\
\hline
\end{tabular}

Conforme observado no Quadro 1, os assentamentos possuem uma variedade de gêneros agrícolas e, os Programas de fomento à Agricultura familiar são os principais meios de comercialização da produção dessas comunidades, sendo que a execução dos mesmos, se dá através de uma maior participação das assentadas.

As lutas históricas de movimentos e organizações sociais para que houvesse, por parte dos governos, reconhecimento das desigualdades de classe e gênero (e outras) vivenciadas no meio rural, foram fatores fundamentais para a criação/qualificação/expansão de Políticas Públicas e Programas que reconhecessem e valorizassem o trabalho das mulheres rurais, compreendidos como instrumentos que potencializam a independência, a autonomia e a emancipação das trabalhadoras rurais, além de dinamizar a produção agrícola.

Na esfera Federal, de acordo com Hora e Butto (2014), dentre as principais Políticas Públicas criadas, é conveniente lembrar que entre os anos de 2003 e 2010, foram formulados uma série de Programas com o objetivo de minimizar os efeitos das desigualdades no campo, das quais, incluíam propostas de empoderamento das mulheres rurais. 
As entrevistadas mencionam que os Programas Governamentais e as Políticas Públicas desenvolvidas em suas comunidades têm uma relação direta com a assistência rural dos técnicos do Instituto de Terras do Estado de São Paulo (ITESP) nos assentamentos, já que são eles que trazem os novos Programas, as formas alternativas de produção (ASSENTADA 1, 2016; ASSENTADA 2, 2016), auxiliam no processo burocrático, na compreensão dos editais e chamadas públicas e dão suporte à reunião dos documentos necessários para a implantação dos mesmos (ASSENTADA 5, 2016).

Os Programas mais mencionados pelas assentadas em suas narrativas foram o Programa de Aquisição de Alimentos (PAA), o Programa Nacional de Alimentação Escolar (PNAE) e o Programa Paulista de Agricultura de Interesse Social (PPAIS). As assentadas da OMAQUESP destacaram ainda que, os produtos destinados à comercialização para esses Programas, em sua maioria, são produzidos pelas mulheres, e que elas, são as mais engajadas e interessadas em buscar conhecer as regras que os editais exigem.

É importante ressaltar que, esses Programas não são direcionados exclusivamente às mulheres rurais, porém, pelo que pode ser observado na realidade dos assentamentos estudados, o interesse na participação dos mesmos, é majoritariamente das assentadas, pois como já destacado, são elas que buscam entender os regulamentos dos Programas, conhecer as regras determinadas pelos editais públicos de cada Programa, no estabelecimento de contatos com os responsáveis nos órgãos e Instituições de Estado e, por isso, são entendidas aqui, como protagonistas na execução do PAA, PNAE e PPAIS.

\section{O PROGRAMA DE AQUISIÇÃO DE ALIMENTOS (PAA)}

O PAA, concebido no âmbito das políticas do Programa Fome Zero, pelo Governo Federal, no ano de 2003 , tem por objetivo, contribuir para o abastecimento de alimentos em escolas, creches e hospitais, visando o fortalecendo da produção de agricultores familiares (MST, 2012).

No Estado de São Paulo, o PAA está presente em 139 assentamentos e beneficia 2611 famílias (INCRA, 2016). Na concepção da Assentada 4 (2016), o PAA é “[...] um projeto surpreendente, muito bom e veio para ajudar a melhorar a qualidade de vida dos assentamentos na compra da nossa produção. A questão é que o PAA paga por ano um valor pequeno [...]".

De acordo com a Companhia Nacional de Abastecimento (CONAB, s.d), responsável pela execução do Programa, os valores máximos pagos anualmente aos agricultores podem chegar a R\$ 8 mil, dependendo da modalidade do PAA (compra direta com doação simultânea, compra direta e se os alimentos serão entregues por família ou por organizações como associações ou cooperativas). 
As assentadas de Araras e Jaboticabal (ASSENTADA 1, 2016; ASSENTADA 4, 2016) destacam que abobrinha, berinjela, laranja, limão, mandioca são os principais produtos que as mesmas destinam ao PAA. Em Jaboticabal, as mulheres assentadas destacaram que já produziram mais de $300 \mathrm{~kg}$ de doce de goiaba, mamão e abóbora, e entregaram ao Programa daquele município (ASSENTADA 4, 2016).

A assentada 4 (2016) ainda revela que são as mulheres que

[...] vêm incansavelmente buscando por avanços no PAA. E a participação nele fez com que muitas fortalecesse a ideia do coletivismo e da participação nos movimentos sociais, porque as que queriam participa, iam tira dúvida com as outras que já tavam e elas passaram a entrega a sua produção, o que vai fazendo com que a gente crie mais independência [...]",

Por mais que os valores máximos pagos anualmente são baixos e que seu aprimoramento seja necessário, conforme comentam as assentadas, o Programa é observado como uma forma de intervenção do Estado no que se refere à compra da produção dos assentamentos, potencializando o trabalho desenvolvido por elas, permitindo que se desvinculem de atravessadores, comercializem diretamente às instituições interessadas (VERONEZZI, 2013), incentivando a diversificação e a autonomia financeira, se configurando como uma das estratégias que fomentam o desenvolvimento local e regional e o trabalho das assentadas.

\section{O PROGRAMA NACIONAL DE ALIMENTAÇÃO ESCOLAR (PNAE)}

O PNAE, também de esfera federal visa, a partir da transferência de recursos da União para Estados e Municípios, adquirir gêneros alimentícios para a alimentação de alunos das Escolas Públicas de Educação Básica. O Programa é vinculado à Fundação Nacional de Desenvolvimento Educacional (FNDE), autarquia federal ligado ao Ministério da Educação (MEC).

As regras do Programa estabelecem que 30\% do total de recursos sejam utilizados para a aquisição de produtos de comunidades tradicionais, da reforma agrária e de áreas indígenas (BRASIL, 2016), o que, segundo a Assentada 3 (2016), assim como o PAA, o PNAE, se torna uma outra possibilidade de obtenção de recursos para as famílias assentadas, já que incentiva a produção de diversas culturas e se torna um meio adicional para destinação dos produtos cultivados nos assentamentos.

Segundo dados disponibilizados no Portal da Transparência (BRASIL, 2016b), no ano de 2013, de fevereiro a dezembro, a Prefeitura Municipal de Araras recebeu R\$ 2.408.296,00 para desenvolver ações de apoio à Alimentação Escolar na Educação Básica e Jaboticabal, R\$ 1.146.072,00 no mesmo período. Desse montante, Araras aplicou, em 2013, na aquisição de produtos específicos da agricultura familiar, cerca de 5\% e Jaboticabal, $21 \%$. No ano seguinte, 2014, Araras disponibilizou pouco mais de $32 \%$ e Jaboticabal, quase $40 \%$ 
do valor total (BRASIL, 2016b) à compra de produtos provenientes da agricultura familiar para fins da alimentação escolar.

Conforme consta na legislação vigente, cada Declaração de Aptidão (DAP) - documento de identificação da agricultura familiar (pessoa física ou jurídica) (BRASIL, 2016c), pode entregar ao Programa até R\$ 20 mil em produtos por ano, o que o torna, segundo as entrevistas, mais atraente que o PAA (ASSENTADA 1, 2016; ASSENTADA 4, 2016; ASSENTADA 6, 2016).

Como exemplo dos produtos adquiridos por meio desse Programa, em julho de 2017, a Prefeitura Municipal de Jaboticabal publicou um edital com o objetivo de credenciar agricultores familiares visando adquirir gêneros alimentícios, constando dentre os itens da chamada pública: abacaxi, abóbora, banana maça, banana nanica, beterraba, cenoura, cebola, chuchu, goiaba, laranja, limão, mandioca, e outros (MDS, 2017), dos quais, vários desses gêneros alimentícios estão presentes na produção do assentamento daquele município e as famílias assentadas participam desse processo de comercialização. "[...] geralmente os editais do PNAE pede produtos bem diversificados e a gente destina a ele nossa produção, porque os preços são interessante [...]", menciona a assentada 1 (2016).

As assentadas da OMAQUESP avaliam que os produtos destinados a esse Programa, em sua maioria, são produzidos pelas mulheres (ASSENTADA 1, 2016; ASSENTADA 4, 2016; ASSENTADA 6, 2016).

\section{O PROGRAMA PAULISTA DE AGRICULTURA DE INTERESSE SOCIAL (PPAIS)}

Em 2011, o Governo do Estado de São Paulo, a partir das demandas das trabalhadoras e trabalhadores do campo, criou o Programa Paulista de Agricultura de Interesse Social, que tem por finalidade fomentar a produção e comprar frutas, verduras e legumes produzidos pelos agricultores familiares, assentados, quilombolas e indígenas do Estado de São Paulo, destinando-os à alimentação de alunos em escolas e universidades, pacientes em hospitais, e detentos em penitenciárias, além de outros órgãos estaduais (SÃO PAULO, 2011).

De acordo com os dados apresentados pelo governo estadual, a Secretaria de Administração Penitenciária do Estado é a que recebe a maioria dos produtos provenientes do PPAIS. Conforme consta na legislação que concebe o Programa, pode participar quem:

I - não detenha, a qualquer título, área maior do que 4 (quatro) módulos fiscais;

II - utilize predominantemente mão de obra da própria família nas atividades econômicas do seu estabelecimento ou empreendimento;

III - tenha renda familiar predominantemente originada de atividades econômicas vinculadas ao próprio estabelecimento ou empreendimento; 
IV - tenha percentual mínimo da renda familiar originada de atividades econômicas do seu estabelecimento ou empreendimento, na forma definitiva pelo Poder Executivo; (redação dada pela Lei no 12.512, de 2011);

V - dirigida seu estabelecimento ou empreendimento com sua família (SÃO PAULO, 2011, s.p).

As assentadas de Jaboticabal contam que estiveram em contato com alguns deputados estaduais quando da época da elaboração desse Programa e que, a criação do mesmo possibilita a complementação da renda das famílias assentadas, tendo como destino certo a produção dos assentamentos. Uma delas relata que: "Foi bom quando começou a funcionar o PPAIS, porque já que a gente é as mais interessada nesses Programas [...], é um dinheiro que vem aumentar nossos recursos" (ASSENTADA 6, 2016).

De encontro com o que destaca a assentada 6 (2016), nesse Programa, o Estado pode chegar a pagar até $\mathrm{R} \$ 22$ mil anuais por família, na compra da produção dos assentamentos, o que mensalmente pode chegar a um valor de $\mathrm{R} \$ 1.800$.

Constatou-se assim, que, os Programas discutidos são desenvolvidos nos assentamentos em questão por meio de uma participação maior das mulheres. Conforme uma das entrevistadas menciona, os homens geralmente não se interessam, pois “[...] eles gostam de cultura que dá mais dinheiro" (ASSENTADA 4, 2016).

O PPAIS, por conta de o rendimento financeiro anual ser maior que o PNAE e o PAA, é considerado pelas mulheres como o mais vantajoso. Há ainda o reconhecimento de que tais Programas contribuem para a diversificação da produção e fortalecimento da agricultura familiar, fomentam o desenvolvimento local e regional, além de valorizar o trabalho das mulheres, que nesse caso, foram as que mostraram maior protagonismo na execução dos mesmos nas comunidades estudadas.

\section{CONSIDERAÇÕES FINAIS}

A realidade agrícola estadual e a dos municípios de Araras e Jaboticabal, é caracterizada pela concentração produtiva de duas culturas: cana-de-açúcar e laranja, commodities do agronegócio. A garantia da diversidade produtiva, nesse contexto concentrador, se dá por meio da produção dos assentamentos rurais, quilombos, áreas de comunidades tradicionais, indígenas e outros, do qual, nesse texto, demonstrouse a participação e o protagonismo das mulheres assentadas, já que são elas, as mais engajadas na execução de Programas Governamentais de fomento à agricultura familiar nas comunidades rurais investigadas.

Nos assentamentos rurais de Araras e Jaboticabal, as assentadas da OMAQUESP, são as principais agentes de execução do PAA, PNAE e o PPAIS, que, são considerados como estratégias que potencializam a 
independência, a autonomia e a emancipação das trabalhadoras rurais, além de dinamizar a produção agrícola.

Dar voz às assentadas permite revelar, a partir de suas experiências de vida, realidades nas quais suas atividades, ao mesmo tempo em que são fundamentais para o desenvolvimento de suas comunidades, também são desvalorizadas, desqualificadas e invisibilizadas, já que, o dia a dia dos assentamentos é marcado pelas desigualdades de gênero (VERONEZZI, 2018).

Além disso, é tarefa essencial inserir a temática de gênero (e as desigualdades de gênero) nas pesquisas geográficas, pois como se observou nesse texto, as possibilidades de investigação em relação às ações das mulheres rurais na transformação do espaço são diversas.

As mulheres organizadas em movimentos sociais e coletivos, como a OMAQUESP, dentre as várias frentes de atuação, buscam desenvolver ações que visam fomentar a luta contra a invisibilidade e pelo reconhecimento de seus trabalhos, construindo estratégias que promovam a diminuição das desigualdades, a transformação de suas comunidades e que contribuam para com o desenvolvimento local e regional.

\section{AGRADECIMENTOS}

À Coordenação de Aperfeiçoamento de Pessoal de Nível Superior/CAPES em cooperação com a Fundação Araucária/FA, pela disponibilização de bolsa de estudos para a realização da tese de Doutorado, da qual parte dessa temática deriva.

\section{REFERÊNCIAS}

ANGELO, José Alberto et al. Previsões e Estimativas das Safras Agrícolas do Estado de São Paulo, Ano Agrícola 2015/16. Análise e Indicadores do Agronegócio, v.11, n.4, abril de 2016.

AGÊNCIA FAPESP. Produção da Agricultura paulista aumenta em mais de $\mathbf{9 0 \%}$ nas últimas décadas. 2016. Disponível em:<http://agencia.fapesp.br/producao_da_agricultura_paulista_aumenta_em_mais_de_90_nas_ultimas_duas_decadas/24008/>. Acesso em: 30 de novembro de 2017.

BRASIL. Fundo Nacional de Desenvolvimento da Educação. Programa Nacional de Alimentação escolar. 2016. Disponível em:<http://www.fnde.gov.br/programas/alimentacao-escolar>. Acesso em: 02 de setembro de 2016.

BRASIL. Fundo Nacional de Desenvolvimento da Educação. Repasses Financeiros: Anos de Referência 2013 e $2014.2016 b$. Disponível em:<http://www.fnde.gov.br/programas/alimentacao-escolar/alimentacao-escolar-consultas/repasses-financeiros>. Acesso em: 31 de março de 2017.

BRASIL. Ministério da Agricultura Familiar e do Desenvolvimento agrário. Declaração de Aptidão ao PRONAF (DAP). 2016c. Disponível em:<http://www.mda.gov.br/sitemda/secretaria/saf/declara\%C3\%A7\%C3\%A3o-de-aptid\%C3\%A3o-ao-pronaf-dap>. Acesso em: 10 de fevereiro de 2016.

CONAB, Companhia Nacional de Abastecimento. O Fortalecimento da Agricultura familiar: o Programa Fome Zero. s.d. Disponível em:<http://www.conab.gov.br/conteudos.php?a=112>. Acesso em: 30 de agosto de 2016. 
INCRA, Instituto Nacional de Colonização e Reforma Agrária. Superintendência de São Paulo. 2016. Disponível em:<http://www.incra.gov.br/sp>. Acesso em: 10 de setembro de 2016.

ITESP. Fundação Instituto de Terras do Estado de São Paulo. Informações dos assentamentos paulistas. 2016. Disponível em:<http://www.itesp.sp.gov.br/>. Acesso em: 10 de abril de 2016.

HORA, Karla. BUTTO, Andrea. Políticas públicas para mulheres rurais no contexto do território da cidadania. In: BUTTO, Andrea; DANTAS, Conceição; HORA, Karla, NOBRE, Miriam; FARIA. Nalu (Orgs). Mulheres rurais e autonomia: formação e articulação para efetivar políticas públicas nos territórios da cidadania. Brasília, MDA, 2014.

MDS. Ministério do Desenvolvimento Social. Chamada Pública 01/2017- Programa Nacional de Alimentação Escola. Prefeitura de Jaboticabal. 2017. Disponível em:

<http://www.mds.gov.br/webarquivos/arquivo/seguranca_alimentar/compra_institucional/2017_editais/PNAE/SP/05072017_PM_J aboticabal.pdf >. Acesso em: 01 de dezembro de 2017.

MENDONÇA, M. L. A OMC e os efeitos destrutivos da indústria da cana no Brasil. Cadernos de Formação, 2, São Paulo, Rede Social de Justiça e Direitos Humanos; Recife, CPT, 2006.

MOURÃO, Patrícia. Organizações produtivas de mulheres rurais. Ministério do Desenvolvimento Agrário (MDA), 2013, s.p.

MST. Movimento dos Trabalhadores Rurais Sem Terra."Governo precisa dobrar valor anual do PAA", diz dirigente do MST. 2012. Disponível em: <

http://www.mst.org.br/PAA-tem-que-reorganizar-estrutura-e-se-tornar-politica-governamental>. Acesso em: 15 de setembro de 2012

NOBRE, Miriam. Relações de gênero e agricultura familiar. In: NOBRE, Miriam; SILIPRANDI, Emma; QUINTELLA, Sandra; MENASCHE, Renata (Orgs). Gênero e agricultura familiar. São Paulo: Cadernos SempreViva, 1998.

OMAQUESP., Organização Estadual de Mulheres Assentadas e Quilombolas do Estado de São Paulo. Estatuto da Organização Estadual de Mulheres Assentadas e Quilombolas do Estado de São Paulo. Araras, 2005.

PACHECO, Maria Emilia Lisboa. Agricultura familiar: Um olhar de gênero. In: NOBRE, Miriam; SILIPRANDI, Emma; QUINTELLA, Sandra; MENASCHE, Renata (Orgs). Gênero e agricultura familiar. São Paulo: Cadernos SempreViva, 1998.

SAFFIOTI, Heleieth; FERRANTE, Vera Lucia Silveira Botta. A mulher e as contradições do capitalismo agrário. Perspectivas, São Paulo, p. 67-75, 1983.

SÃO PAULO (Estado). Secretaria de Agricultura e Abastecimento. Coordenadoria de Assistência Técnica Integral. Instituto de Economia Agrícola. Levantamento censitário de unidades de produção agrícola do Estado de São Paulo - LUPA 2007/2008. São Paulo: SAA/CATI/IEA, 2008

SÃO PAULO (Estado). Coordenadoria de Assistência Técnica Integral. Programa Paulista da Agricultura de Interesse Social. 2011. Disponível em:<http://www.cati.sp.gov.br/ppais/oprograma.html>. Acesso em: 30 de agosto de 2016.

SILVA, Joseli Maria. Um ensaio sobre as potencialidades do uso do conceito de gênero na análise geográfica. Revista de História Regional, p.31-45, 2003.

VELEDA DA SILVA, Susana Maria. Os estudos de gênero no Brasil-algumas considerações. Revista Bibliográfica de Geografia y Ciencias Sociales. Universidad de Barcelona, novembro, 2000, s.p.

VELEDA DA SILVA, Susana Maria. A contribuição dos estudos de gênero para uma compreensão da Geografia do Trabalho: uma pauta para discussão. Revista Latino-americana de Geografia e Gênero, Ponta Grossa, p. 106-117, agosto/dezembro, 2013.

VERONEZZI, Fernando. A Cultura Canavieira e seus efeitos nos municípios que compõem o Escritório de Desenvolvimento Rural (EDR) de Jaboticabal - São Paulo. Revista Percurso, Maringá, p. 95- 111, 2012.

VERONEZZI, Fernando. Os trabalhadores rurais e a luta pela terra na região de Jaboticabal (SP): A conquista do assentamento rural de Córrego Rico. 2013. 145f. Dissertação (Mestrado em Geografia). Universidade Estadual de Maringá, Maringá-PR.

VERONEZZI, Fernando. Resistência, empoderamento e emancipação: as militantes da organização de mulheres assentadas e quilombolas do estado de São Paulo (OMAQUESP). 2018. 171 f. Tese (Doutorado em Geografia) - Universidade Estadual de Maringá, Maringá, 2018.

\section{ENTREVISTAS}

Assentada 1, 50 anos, solteira, assentada, militante e participante de outros movimentos sociais, Sindicatos, Federações, Confederações. Entrevista concedida em Araras-SP, 2016. 
Assentada 2, 42 anos, casada, assentada, militante e participante de outros movimentos sociais. Entrevista concedida em Araras-SP, 2016.

Assentada 3, 47 anos, casada, assentada, militante e participante de outros movimentos sociais. Entrevista concedida em Araras-SP, 2016.

Assentada 4, 46 anos, casada, assentada, militante e participante de outros movimentos sociais, Sindicatos, Federações, Confederações. Filiada a um partido político. Entrevista concedida em Jaboticabal,-SP, 2016.

Assentada 5, 52 anos, casada, assentada e militante. Entrevista concedida em Jaboticabal,-SP, 2016.

Assentada 6, 49 anos, casada, assentada, militante e participante de outros movimentos sociais, Sindicatos, Federações, Confederações. Entrevista concedida em Jaboticabal,-SP, 2016. 